\title{
Fabrication and Evaluation of Nanostructured Herbal Oil/ Hydroxypropyl- $\beta$-Cyclodextrin/Polyvinylpyrrolidone Mats for Denture Stomatitis Prevention and Treatment
}

\author{
Prasopchai Tonglairoum, ${ }^{1}$ Tanasait Ngawhirunpat, ${ }^{1}$ Theerasak Rojanarata, ${ }^{1}$ \\ Ruchadaporn Kaomongkolgit, ${ }^{2}$ and Praneet Opanasopit ${ }^{1,3}$
}

\begin{abstract}
Received 22 October 2015; accepted 3 January 2016; published online 28 January 2016
Abstract. This work aims to develop the herbal oil-incorporated nanostructure mats with antifungal activity for the prevention and treatment of Candida-associated denture stomatitis. The nanofiber mats loaded with betel oil or clove oil were fabricated via electrospinning process. The morphologies and physicochemical properties of the herbal oil loaded nanofiber mats were examined using scanning electron microscopy (SEM), Fourier transform infrared spectroscopy (FT-IR), differential scanning calorimetry (DSC), and mechanical testing. The release characteristic, antifungal activity, and cytotoxicity were also investigated. The SEM images confirmed the homogeneous and smooth nanoscale fibers. The addition of the herbal oil into the nanofiber mats reduced the fiber diameters. The DSC and FT-IR results confirmed the presence of the oil in the nanofiber mats. The herbal oils can be released from the mats in a very fast manner and inhibit the growth of candida cells within only few minutes after contact. These nanofiber mats may be beneficial for the prevention and treatment of denture stomatitis.
\end{abstract}

KEYWORDS: betel oil; clove oil; hydroxypropyl-beta-cyclodextrin; nanofibers; polyvinylpyrrolidone.

\section{INTRODUCTION}

Even though there has been great medical advancement, the increment in the prevalence of the opportunistic oral fungal infection has been observed, especially in denture wearers. Poor oral hygiene and several systemic factors are the most probable initial causes of this infection (1).The oral fungal infection induced by wearing denture with inflammation and erythema of the oral mucosal areas covered by the denture can be defined as denture stomatitis (2-4). Poor denture and oral hygiene are believed to be critical risk factors for denture stomatitis. In addition to poor hygiene, unceasing denture wearing can boost opportunistic overgrowth of pathogenic yeasts, such as Candida (2). Candida albicans is a commensal of the microbial communities of the human oral cavity, and it has been shown to be the dominant strain responsible for oral candidiasis and Candida-associated denture stomatitis (2). Maintaining good oral and denture hygiene and

Electronic supplementary material The online version of this article (doi:10.1208/s12249-016-0478-2) contains supplementary material, which is available to authorized users.

${ }^{1}$ Pharmaceutical Development of Green Innovations Group (PDGIG), Faculty of Pharmacy, Silpakorn University, NakhonPathom, Thailand.

${ }^{2}$ Department of Oral Diagnosis, Faculty of Dentistry, Naresuan University, Phitsanulok, Thailand.

${ }^{3}$ To whom correspondence should be addressed. (e-mail: opanasopit_p@su.ac.th) balancing the oral microflora could help to prevent denture stomatitis.

Natural products as traditional therapeutics are in considerable demand, as they are comprehended to have minimal side effect on humans (5). Recently, a variety of herbal products are encouraged for oral and dental uses as alternative to standard commercial products. Some herbal compounds have effective antimicrobial effects, and many herbal components such as chamomile, clove oil, echinacea, eucalyptus, ginger, etc. are included in herbal oral products (6). Piper betle Linn. (betel) is a tropical plant closely related to the common pepper. It is a traditional herb that has been used as mouthwash, dental medicine, cough medicine, astringent, tonic, and others. The extract of betel leaves has been reported to demonstrate antioxidative, antiinflammatory, antibacterial, and antifungal activities (7-9). Another plant is Syzygium aromaticum (clove) which is one of the interesting plants with antifungal activity. The clove oil from S. aromaticum and eugenol are wildly used in dental medicine because they exhibit useful antiseptic, analgesic, and anaesthetic effects $(10,11)$. Some research studies have reported antifungal activity of clove oil and eugenol against several yeasts and fungi (10-13). Clove oil and eugenol have also been evaluated as antifungal agents in animal models (14).

In the recent past, new tactics for drug delivery have gained much attention. The considerable advantages of fast dissolving drug delivery systems such as enhanced drug solubility, onset of action, and bioavailability make this system more fascinating $(15,16)$ However, the selection of appropriate polymer that can dissolve rapidly and easily is required to 
accomplish the fast dissolution. Polyvinylpyrrolidone (PVP) is one of the desirable polymers that can provide these features; it is capable of ultrafast dissolution. Cyclodextrins (CDs) are cyclic oligosaccharides consisting of 1,4-linked glucopyranoside units having either six, seven, or eight glucose units arranged in a cyclic structure with a hydrophilic outer surface and a lipophilic central cavity which suit for a variety of lipophilic drugs $(17,18)$. Because the physicochemical properties of incorporated compounds can be oriented by complexation with CDs, the CDs are employed in many application fields, such as pharmaceuticals, foods, cosmetics, home/personal care, textiles, and so on $(18,19)$.

Recent advances in nanotechnology and increasing recognition of the potential of nanomaterials in many fields of application lead to a surging interest in the fabrication and development of nanofibrous scaffolds. Nanofiber materials demonstrate outstanding characteristics such as low density, high porosity, large specific surface areas, and very small pore sizes. They have been applied in many areas (tissue engineering, drug delivery systems, wound dressing, filtration, etc.) (20-22) One of the marvelous methods that can be used to generate nanofibers is electrospinning. Electrospinning is a process that uses an electric field to control the formation and generation of polymers. This process is remarkably efficient, rapid, and inexpensive (23).

Until now, there are only a limited number of studies that investigate the incorporation of volatile oil into the nanofiber. We have successfully incorporated plain oil-CDs inclusion complex into electrospun fibers for topical application (18). In this study, the betel oil or clove oil was incorporated into the PVP nanofiber mats using electrospinning process with the assistance of CDs. The morphology and structure as well as physicochemical properties of the PVP/HP $\beta C D$ nanofiber and herbal oil loaded PVP/HP $\beta C D$ nanofiber were investigated. Moreover, the release of the oil from the nanofiber mats, antifungal activity against oral fungi, and cytotoxicity was also evaluated.

\section{MATERIALS AND METHODS}

\section{Materials}

Polyvinylpyrrolidone (PVP, MW. 1,300,000) and 2hydroxypropyl- $\beta$-cyclodextrin $(\mathrm{HP} \beta \mathrm{CD})$ were purchased from Sigma-Chemical Co. (St. Louis, MO, USA). Betel oil and clove oil were obtained from the Thai China Flavours and Fragrances Industry Co., Ltd., Thailand. Sabouraud dextrose broth was purchased from Becton, Dickinson and Company (Franklin Lakes, NJ, USA). All other reagents were used without further purification. Artificial saliva was composed of $2.38 \mathrm{~g} \mathrm{Na}_{2} \mathrm{HPO}_{4}, 0.19 \mathrm{~g} \mathrm{KH}_{2} \mathrm{PO}_{4}$, and $8 \mathrm{~g}$ of $\mathrm{NaCl}$ per liter of distilled water adjusted with the phosphoric acid to $\mathrm{pH} 6.8$ \pm 0.05 . Human gingival fibroblast cells (HGF) obtained from explants of gingival tissue attached to non-carious, freshly extracted third molars from three patients. All patients provided informed consent before tissue collection. Ethical approval for the study was obtained from Naresuan University.

\section{Fabrication of Nanostructured Mats}

The polymer solutions were prepared by dissolution of PVP in 50:50 volume ratio of ethanol to water mixture at the concentration of $8 \%$ (by weight). After which, varied amounts of $\mathrm{HP} \beta \mathrm{CD}$ (90-190 $\mathrm{mM}$ ) were added to the polymer solutions. The polymer solutions were stirred using a magnetic stirrer for several hours until homogenous solutions were obtained. The solutions were spun into a nanofiber using electrospinning process at room temperature. In this process, the spinning solution was placed in a 5-ml glass syringe connected to a stainless steel needle with a $0.9-\mathrm{mm}$ inner diameter. The needle was connected to an emitting electrode with a positive polarity of a Gamma High Voltage Research device. The electrospinning process was conducted with a fixed applied voltage of $15 \mathrm{kV}$, a distance between the tip and the collector of $15 \mathrm{~cm}$, and a feeding rate of $0.4 \mathrm{ml} / \mathrm{h}$. The electrospun nanofibers were collected on an aluminum foil covering the rotating collector.

\section{Fabrication of Herbal Oil Loaded Nanofiber Mats}

To fabricate the herbal oil loaded nanofibers, betel oil or clove oil (20-40\% weight to polymers) was added to the polymer solution containing $150 \mathrm{mM}$ HP $\beta C D$. The mixtures were stirred for $24 \mathrm{~h}$ to allow the oil incorporate into the HP $\beta C D$. After which, the mixtures underwent electrospinning process as previously mentioned to obtain the herbal oil loaded nanofiber mats. The content of the oils from the betel oil or clove oil loaded nanofiber mats was determined to select the suitable percentage to be incorporated.

\section{Characterization of the Nanofibers}

\section{Scanning Electron Microscope}

The morphological appearances and diameters of the nanofiber mats were observed $(3000 \times)$ using a scanning electron microscope (SEM, Camscan M $\times 2000$, England). Samples were prepared by cutting the nanofiber and attaching them on aluminum stubs. After that, the samples were then gold sputtering coated before the SEM observations. The average diameters of the fibers were analyzed using an image analysis software (JMicroVision V.1.2.7, Switzerland).

\section{Fourier Transform Infrared Spectrophotometry}

The Fourier transform infrared spectroscopy was carried out using a Fourier transform infrared spectrophotometer (FT-IR, Nicolet 4700, USA) with a wave number range of $400-4000 \mathrm{~cm}^{-1}$ to confirm the incorporation of the herbal oil in the nanofiber mats. The fiber samples were ground and pressed into $\mathrm{KBr}$ dishes prior to the FT-IR analysis. The used resolution and number of scans were 4 and 32, respectively.

\section{Differential Scanning Calorimetry}

A differential scanning calorimeter (Pyris Diamond DSC, PerkinElmer instrument, USA) was used to determine the thermal behavior of the herbal oil loaded nanofiber mats. The experiments were conducted using dry samples, under nitrogen flow, weighing approximately $5 \mathrm{mg}$. The DSC traces were recorded from 50 to $250^{\circ} \mathrm{C}$ at $10^{\circ} \mathrm{C} / \mathrm{min}$. 


\section{Mechanical Characterizations}

Tensile testing of the nanofiber was investigated using a texture analyzer (TA.XT plus, Stable Micro Systems, UK) by applying a 5-kg load cell equipped with tensile grip holder. All samples were cut into rectangle shapes with dimensions of $25 \times 5 \mathrm{~mm}^{2}$.

\section{Ex vivo Mucoadhesion Assay}

The ex vivo mucoadhesive study was performed according to a previous study (24). Mucoadhesive force of nanofiber mats onto porcine buccal mucosa were performed using a texture analyzer (TA.XT plus, Stable Micro Systems, UK) equipped with a $5-\mathrm{kg}$ load cell. The porcine cheek pouches were employed as the model surface for the mucoadhesion assay. After the cheek pouches were excised and trimmed in a regular way, they were rinsed with simulated saliva and then used right away. The nanofiber mats were cut into circular shapes with a diameter of $13.7 \mathrm{~cm}$ and then fixed to a cylindrical Perspex support (diameter $2 \mathrm{~cm}$, length $4 \mathrm{~cm}$, surface area $3.14 \mathrm{~cm}^{2}$ ) using a double-sided adhesive tape. During the experiment, $500 \mu \mathrm{L}$ of artificial saliva was dispersed on the surface of the tissue. The probe moved down at a speed of $2 \mathrm{~mm} \mathrm{~s}^{-1}$ until it contacted the tissue at a force of $0.3 \mathrm{~N}$ for a contact time of $15 \mathrm{~s}$.

\section{Determination of the Oil Content}

The total amounts of the oil incorporated in the nanofiber mats were quantified in triplicate using UV-visible spectrophotometer (Agilent G1103A UV-Vis Spectrophotometer, Agilent Technologies, USA) at $279 \mathrm{~mm}$. Accurately weighed samples $(10 \mathrm{mg})$ of the fiber mats were dissolved in $1 \mathrm{ml}$ of ethanol and were continuously shaken in an incubator (Orbital Shaking Incubator Model: SI4) at $150 \mathrm{rpm}$ for $24 \mathrm{~h}$. The experiments were performed in triplicate. The loading capacity was calculated according to Eq. (1):

Loading capacity $=\mathrm{P}_{\mathrm{t}} / \mathrm{M}_{\mathrm{t}}$

where $P_{t}$ is the amount of oil $(\mu \mathrm{g})$ embedded in the nanofiber mats and $M_{t}$ is the weight of nanofiber mats $(\mathrm{mg})$.

\section{In vitro Release}

The in vitro release studies were adapted from those of Singh et al. (25). Briefly, $10 \mathrm{mg}$ of the herbal oil loaded nanofiber mats was placed in a $50-\mathrm{ml}$ bottle containing $20 \mathrm{ml}$ of artificial saliva ( $\mathrm{pH}$ 6.8) that was incubated at $37^{\circ} \mathrm{C}$ and shaken at $150 \mathrm{rpm}$. To determine the amount of the oil released from the fiber mats after a given interval, an aliquot $(1.0 \mathrm{ml})$ of the release medium solution was withdrawn and replaced with the same volume of fresh medium to maintain a constant volume. The amounts of oil in the sample solutions were analyzed by UV-visible spectrophotometer (Agilent G1103A UV-Vis Spectrophotometer, Agilent Technologies, USA). The experiments were conducted in triplicate.

\section{Antifungal Activities}

\section{Candida Strains and Inoculum Preparation}

The ATCC 90028 strain of oral C. albicans was used in this study. Sabouraud dextrose broth (SDB) was used to revive the culture. An active culture was prepared by inoculating fresh nutrient broth medium with a loop full of cells from
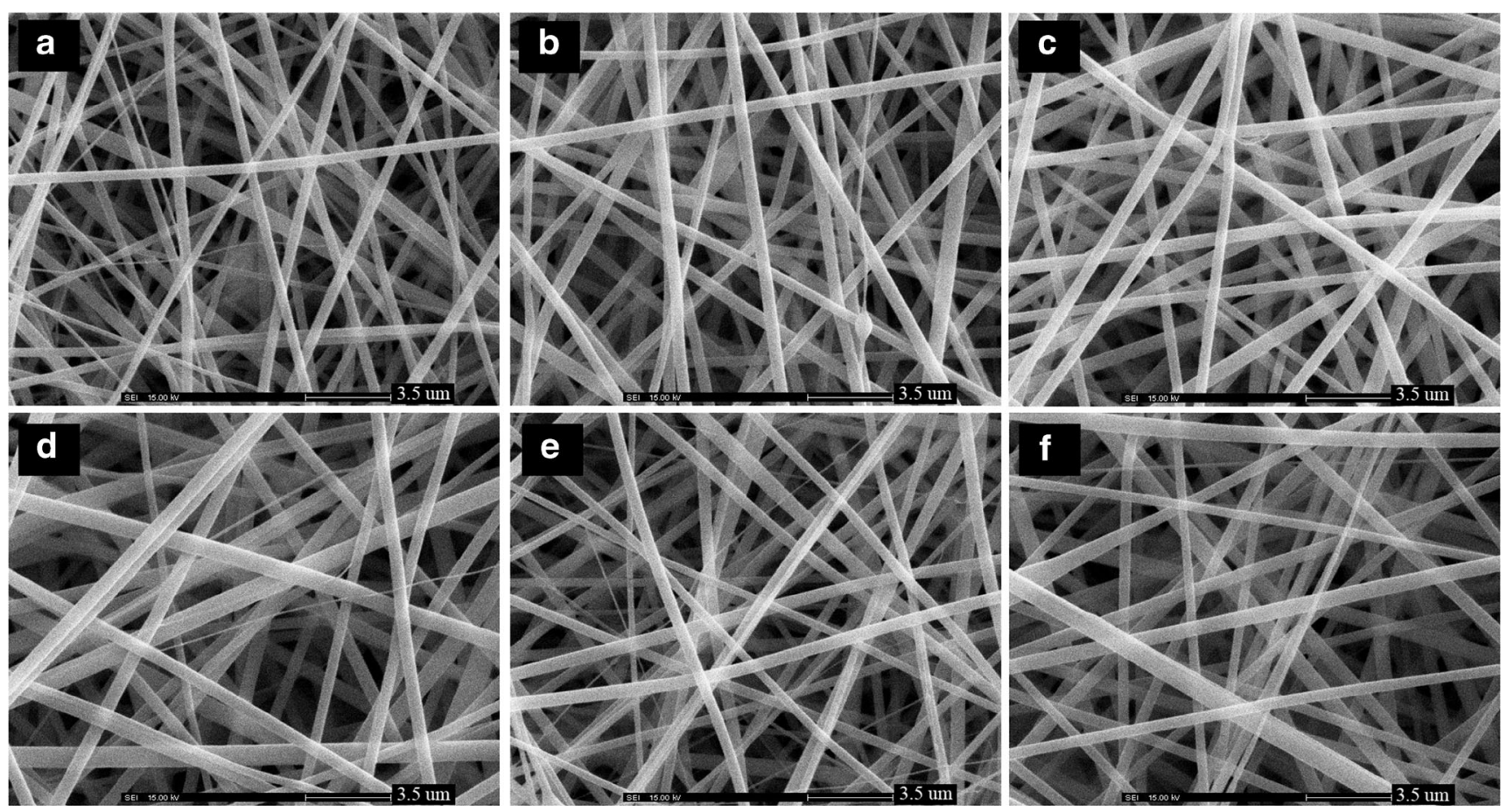

Fig. 1. SEM images $(3000 \times)$ of $8 \%$ PVP nanofiber mats with different amounts of HPßCD a $90 \mathrm{mM}, \mathbf{b} 110 \mathrm{mM}, \mathbf{c} 130 \mathrm{mM}, \mathbf{d} 150 \mathrm{mM}$, e $170 \mathrm{mM}$ and $\mathbf{f} 190 \mathrm{mM}$ 


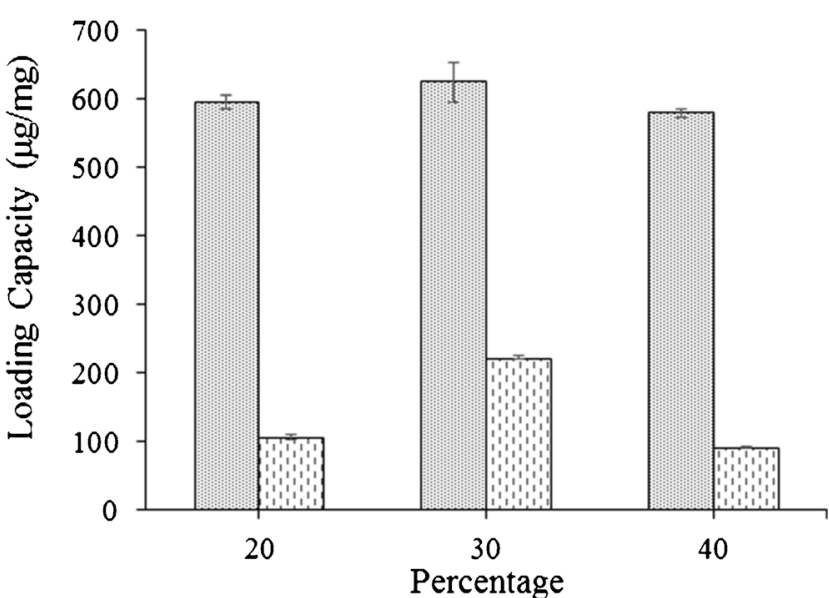

Fig. 2. Loading capacity of (闻) betel oil loaded nanofiber mats and (1. clove oil loaded nanofiber mats containing 20,30 , and $40 \%$ of the oils loaded

stock cultures at $37^{\circ} \mathrm{C}$ overnight. The candida suspensions were diluted in SDB and spectrophotometrically standardized to $1 \times 10^{6} \mathrm{CFU} / \mathrm{ml}$ (Perkin Elmer Lambda 2, Germany).

\section{Antifungal Activity of Betel Oil and Clove Oil}

The antifungal activity of betel oil and clove oil were determined via assessing susceptibility of C. albicans toward the oils using broth microdilution assay in accordance with the guidelines recommended by the CLSI (Clinical and Laboratory Standards Institute, 2002). Briefly, C. albicans were incubated $\left(10^{4} \mathrm{CFU} / \mathrm{ml}\right)$ in 48 -well plates for $24 \mathrm{~h}$ at $37^{\circ} \mathrm{C}$ after being exposed to serial twofold dilutions of the herbal oil in SDB culture medium (from 100 to $0.05 \mu \mathrm{L} / \mathrm{ml}$ ). The results were expressed as the minimum inhibitory concentration (MIC) and minimum fungicidal concentration (MFC) toward Candida cells.

\section{Time-kill Curve Studies}

The time-kill analyses were performed as previously described protocol (26) using SDB. Ten microliters of the adjusted inoculum suspension (approximately $1 \times 10^{6} \mathrm{CFU} / \mathrm{ml}$ ) was dispensed into a plastic Eppendorf tube containing $1 \mathrm{ml}$ of $\mathrm{SDB}$, providing the starting inoculum of approximately $1 \times 10^{4} \mathrm{CFU} / \mathrm{ml}$. The samples of the herbal oil loaded nanofiber mats with varied oil were incubated with Candida suspensions under agitation at $37^{\circ} \mathrm{C}$. After the predetermined contact times $(5,15,30,60$, and $120 \mathrm{~min})$, small aliquots of the samples were removed, and the microorganisms were counted by spreading each sample onto an SDA agar plate. The plates were incubated for $24 \mathrm{~h}$, and the viable colonies were counted. The kill curves were constructed by plotting the $\mathrm{CFU} / \mathrm{ml}$ surviving at each time point in the presence and absence of the nanofiber mats.

\section{In vitro Cytotoxicity}

The HGF cells obtained from explants of gingival tissue attached to non-carious, freshly extracted third molars from three patients were used to examine the compatibility of the blank nanofiber mats and herbal oil loaded nanofiber mats. The cytotoxicity tests were performed based on a procedure adapted from the ISO10993-5 standard testing method (indirect contact). The HGF cells were cultured in DMEM medium supplemented with 10\% FBS, 2 mM l-glutamine, 1\% nonessential amino acids, and $0.1 \%$ penicillin-streptomycin at $37^{\circ} \mathrm{C}$ in humidified $5 \% \mathrm{CO}_{2}$ atmosphere. The cells were seed at a density of 10,000 cells/well in 96-well plates for $24 \mathrm{~h}$ before sample treatment. The nanofibers were sterilized using UV radiation for $45 \mathrm{~min}$ before being immersed in a serum-free medium (SFM; containing DMEM, 1\% l-glutamine, 1\% lactalbumin, and $1 \%$ antibiotic and antimycotic formulation) and incubated for $24 \mathrm{~h}$ to produce extraction media with varying concentrations. The extraction media at varying concentrations were replaced, and the cells were re-incubated for 2 and $24 \mathrm{~h}$. After treatment, the tested extraction solutions were removed, and the cytotoxicity was determined by MTT assay. The relative viability (\%) was calculated based on the absorbance at $550 \mathrm{~nm}$ determined using a microplate reader (Universal Microplate Analyzer, Model AOPUS01 and AI53601, Packard BioScience, CT, USA). The viability of non-treated control cells was defined as $100 \%$.

\section{Statistical Analysis}

All experimental measurements were collected in triplicate. The values are expressed as the mean \pm standard deviation (SD). The statistical significance of the differences in each experiment was examined using one-way analysis of variance (ANOVA), followed by a least significant difference (LSD) post hoc test. The differences were significant at $p<0.05$.

\section{RESULTS AND DISCUSSION}

\section{Fabrication of Betel Oil or Clove Oil Loaded Nanofiber Mats}

To fabricate the nanofiber, the amounts of $\mathrm{HP} \beta \mathrm{CD}$ were varied in the range of 90-190 $\mathrm{mM}$ because adding the $\mathrm{HP} \beta \mathrm{CD}$

Table I. The Mechanical Properties, Mucoadhesive Strength and Loading Capacity of Blank Nanofiber Mats and Betel Oil or Clove Oil Loaded Nanofiber Mats

\begin{tabular}{lccc}
\hline Nanofiber mats & Young's modulus $(\mathrm{MPa})$ & Mucoadhesive strength $(\mathrm{mg})$ & Loading capacity $(\mu \mathrm{g} / \mathrm{mg})$ \\
\hline PVP/HP $\beta$ CD nanofiber mats & $0.69 \pm 1.12$ & $26.0 \pm 0.6$ & - \\
$30 \%$ betel oil loaded mats & $3.58 \pm 0.36$ & $34.0 \pm 0.6$ & $624.8 \pm 28.7$ \\
$30 \%$ clove oil loaded mats & $1.84 \pm 0.14$ & $29.0 \pm 2.5$ & $222.1 \pm 9.7$ \\
\hline
\end{tabular}




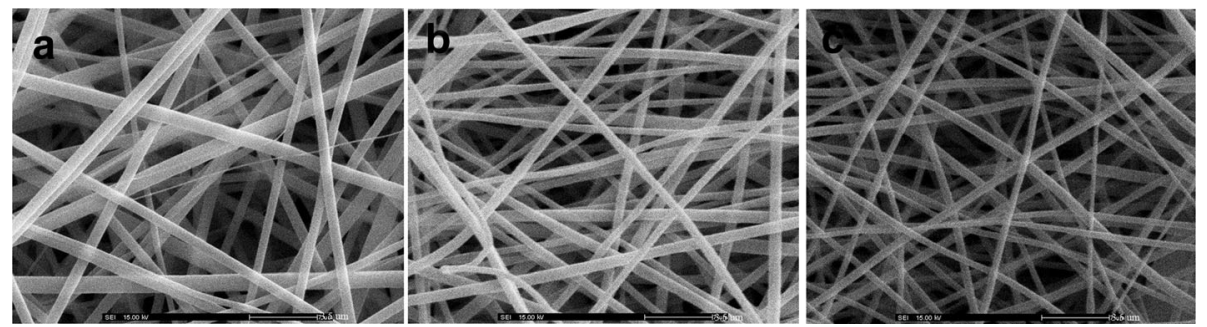

Fig. 3. SEM images of a $8 \%$ PVP $/ 150 \mathrm{mM} \mathrm{HP} \beta C D$ nanofiber mats, b $8 \%$ PVP $/ 150 \mathrm{mM} \mathrm{HP} \beta C D$ nanofiber mats loaded with $30 \%$ betel oil, $\mathbf{c} 8 \%$ PVP/150 mM HP $\beta C D$ nanofiber mats loaded with $30 \%$ clove oil

could help in reducing the hygroscopic property of PVP. In addition, HP $\beta C D$ could entrap the medicinal oil and increase the solubility of the oil (18). Figure 1 shows the SEM images of the PVP nanofiber mats containing different amount of HP $\beta C D$. The nanofiber mats had a smooth surface without bead. Increasing the amounts of $H P \beta C D$ resulted in the increase in diameters of the nanofiber mats. The diameters of the nanofibers containing 90 to $190 \mathrm{mM} \mathrm{HP} \beta C D$ were in the range of $394.40 \pm 45.17$ to $496.07 \pm 125.65 \mathrm{~nm}$. The nanofiber mat with $150 \mathrm{mM}$ was selected for further investigation because this is the highest amount of $\mathrm{HP} \beta C D$ that can be loaded into the nanofibers with good physical textures.

After known the appropriate amount of $\mathrm{HP} \beta \mathrm{CD}$ to be used, the amount of oils was varied from 20 to $40 \%$ weight to polymer. The $8 \% w / v \mathrm{PVP} / 150 \mathrm{mM} \mathrm{HP} \beta \mathrm{CD}$ solution containing various amounts of betel oil or clove oil (containing 20, 30 and $40 \mathrm{wt} \%$ to polymer) was prepared, and the betel oil or clove oil loaded nanofiber mats were successfully fabricated. The loading capacity of these betel oil or clove oil loaded nanofiber mats were determined and were presented in Fig. 2. It can be seen from the results that after increasing the amount of oil from 20 to $30 \%$, the loading capacity values increased. The $30 \%$ betel oil loaded nanofiber mats and the $30 \%$ clove oil loaded nanofiber mats demonstrated the highest loading capacity. The increase in amount of the oil loading from 30 to $40 \%$ resulted in the decrease in the amount of betel oil or clove oil entrapped in the nanofiber mats. This may be due to the capacity of nanofiber mats that can carry the oils with the maximum amount at $30 \%$. There were some variations in the loading capacity between both oils. The results revealed that $30 \%$ betel oil loaded mats showed higher loading capacity than $30 \%$ clove oil loaded mat (Table I). This may be due to the difference in composition and properties of these oils $(27,28)$. Thus, $30 \%$ betel oil and $30 \%$ clove oil were selected to be incorporated into the nanofiber mats for further investigations.

The SEM images of the blank PVP/HP $\beta C D, 30 \%$ betel oil-loaded, and $30 \%$ clove oil loaded nanofiber mats are illustrated in Fig. 3. The SEM images revealed beadfree and smooth fibers without delamination or phase separation of the oils from the nanofiber mats which confirmed the interaction of the oil with the polymer. The addition of the oils into the nanofiber reduced the fiber diameters. The HP $\beta C D$ added into the polymer solution could entrap the oil into it and help protect the polymer from melting (18). The diameters of the oil loaded fibers were in the range of $396.56 \pm 65.31$ to 425.89 $\pm 82.28 \mathrm{~nm}$.

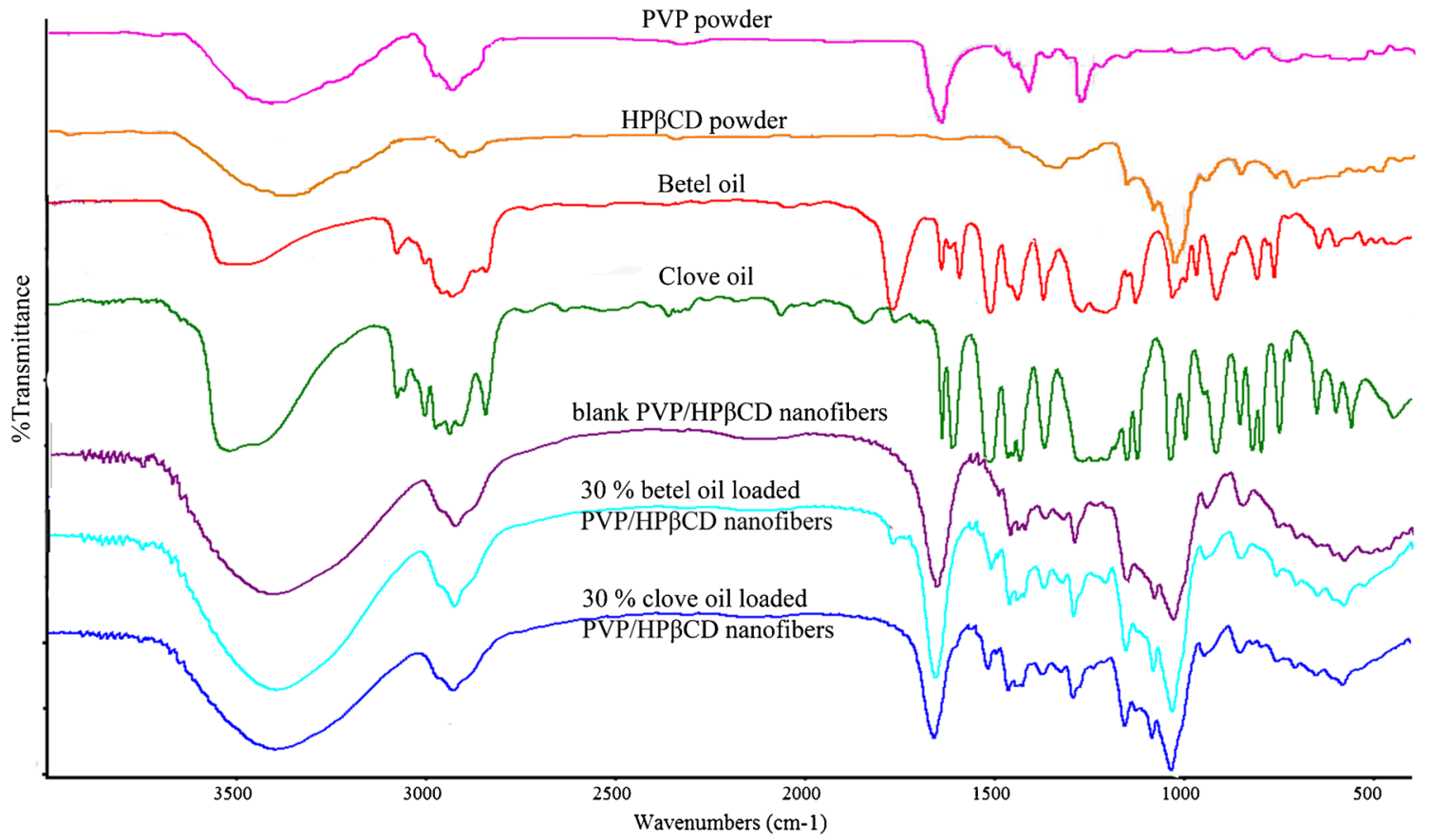

Fig. 4. FT-IR spectra of PVP, HP $\beta C D$, blank PVP/HP $\beta C D$ nanofiber mats, betel oil, clove oil, blank PVP/HP $\beta C D$ nanofibers, $30 \%$ betel oil loaded PVP/HP $\beta C D$ nanofibers, and $30 \%$ clove oil loaded PVP/HP $\beta C D$ nanofibers 


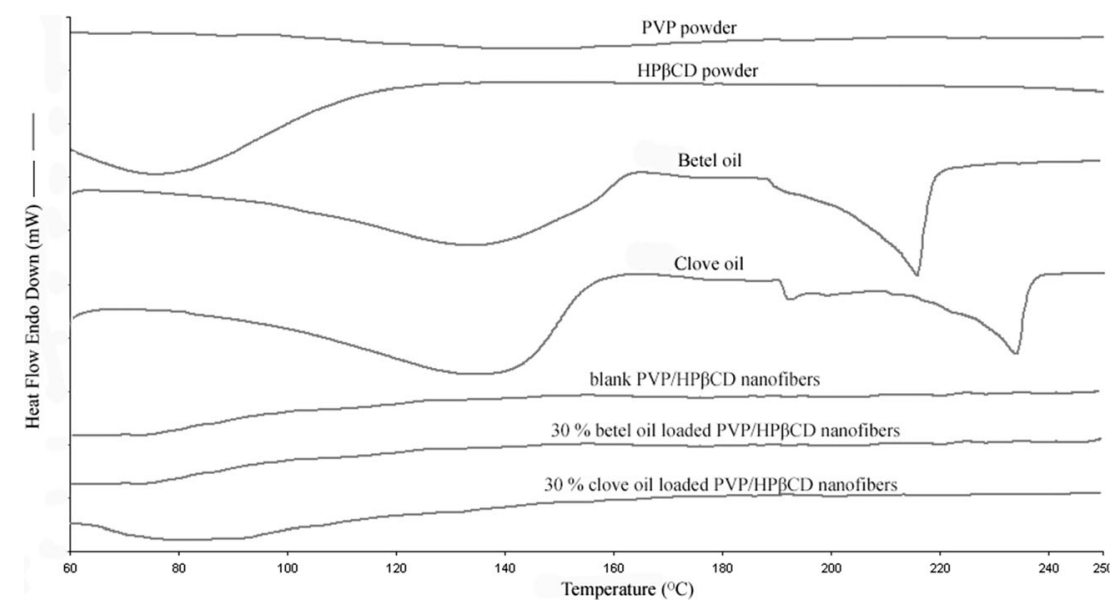

Fig. 5. DSC thermograms of PVP powder, HP $\beta$ CD powder, betel oil, clove oil, blank PVP/HP $\beta$ CD nanofibers, $30 \%$ betel oil loaded PVP/ $\mathrm{HP} \beta \mathrm{CD}$ nanofibers, and $30 \%$ clove oil loaded PVP/HP $\beta$ CD nanofibers

\section{FT-IR Analysis}

The FT-IR spectra of PVP, HP $\beta$ CD, betel oil, clove oil, PVP/HP $\beta C D$ nanofiber mats, betel oil loaded nanofiber mats and clove oil loaded nanofiber mats are shown in Fig. 4. The spectrum of PVP presented peaks at 3452.2 , $2926.5,1663.4,1415.7$, and $1290.1 \mathrm{~cm}^{-1}$ that were attributed to $\mathrm{N}-\mathrm{H}, \mathrm{CH}_{2}, \mathrm{C}=\mathrm{O}, \mathrm{C}-\mathrm{N}$ stretching vibration, and $\mathrm{C}-\mathrm{H}$ bending, respectively (29). The peaks at 3423.7, 2915.4, 1167.8 , and 1083.7 of the HP $\beta C D$ spectrum corresponded to $\mathrm{O}-\mathrm{H}, \mathrm{C}-\mathrm{H}, \mathrm{C}-\mathrm{H}$, and $\mathrm{C}-\mathrm{O}$ stretching vibrations, respectively (30). The pure PVP/HP $\beta$ CD nanofiber mats exhibited absorption peaks as observed in the spectra of PVP and HP $\beta C D$. The spectrum of betel oil and clove oil exhibited absorption peaks at $3514.0,3077.1$, and $2932.3 \mathrm{~cm}^{-1}$ that were attributed to $\mathrm{O}-\mathrm{H},=\mathrm{C}-\mathrm{H}$, and $\mathrm{C}-\mathrm{H}$ stretching, respectively (31). The bands at 1602.4 and 1510.8 corresponded to aromatic $\mathrm{C}=\mathrm{C}$ stretching (32). The spectrum of betel oil and clove oil loaded nanofiber mats displayed all features of the peaks that were observed in the spectrum of $\mathrm{PVP} / \mathrm{HP} \beta \mathrm{CD}$, betel oil, and clove oil. It seems to be the evidence for the present of the herbal oil in the nanofiber mats. Especially, the bands of aromatic $\mathrm{C}=\mathrm{C}$ stretching of the betel oil and clove oil spectra that were generally not observed in the

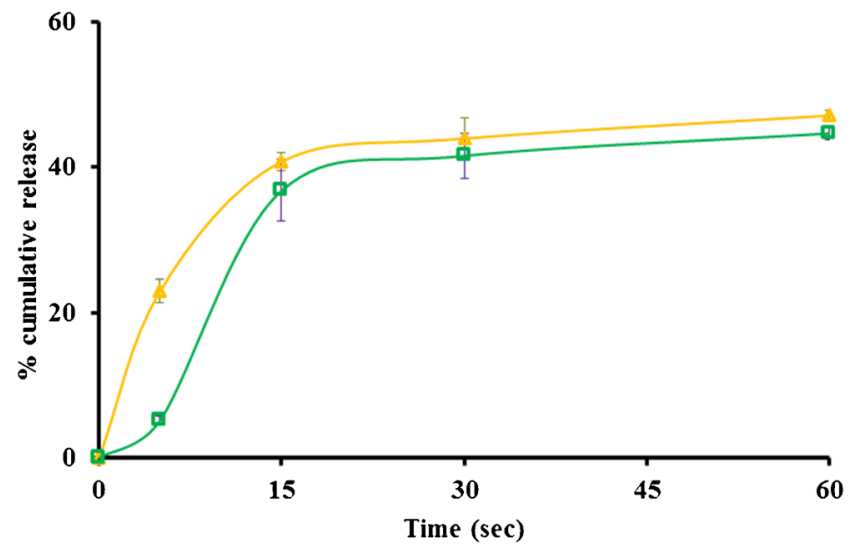

Fig. 6. Release profile of (triangle) betel oil and (square) clove oil from the PVP/HP $\beta C D$ nanofiber mats. The data are expressed as mean \pm standard deviation from three independent experiments spectrum of $\mathrm{PVP} / \mathrm{HP} \beta \mathrm{CD}$ were found in the spectrum of betel oil and clove oil loaded nanofiber mats.

\section{Differential Scanning Calorimetry}

Differential scanning calorimetry (DSC) studies were carried out to investigate the thermal behavior of the betel oil and clove oil in the electrospun nanofiber mats, and the thermograms are displayed in Fig. 5. Pure betel oil and pure clove oil exhibited endothermic peaks related to the process of evaporation at 216.1 and $233.4^{\circ} \mathrm{C}$, respectively. The thermograms of the blank nanofiber mats and the betel oil or clove oil loaded nanofiber mats were quite similar. This indicated that the incorporation of betel oil and clove oil into the nanofiber mats did not affect the thermal properties of the nanofiber mats.

\section{Mechanical Properties}

The mechanical properties in terms of Young's modulus of the PVP/HP $\beta C D$ nanofiber mats with and without the herbal oils loading were determined using a texture analyzer, and the results are displayed in Table I. The Young's modulus values of all tested nanofiber mats were in the range of 0.69 $3.58 \mathrm{MPa}$. Adding the oil into the nanofiber did not have negative effect on the tensile strength of the nanofiber mats, but it improved the mechanical properties of the mats. The $30 \%$ betel oil loaded nanofiber mats demonstrated the highest value of Young's modulus.

\section{Ex vivo Mucoadhesion Assay}

The ex vivo mucoadhesion studies were carried out to evaluate the ability of the mats to adhere to the mucous within the mouth. The results of the mucoadhesion assay are listed in Table I. The mucoadhesive strengths of all nanofiber mats were in the range of $26-34 \mathrm{mg}$. The loading of the herbal oils into the nanofiber did not diminish the mild mucoadhesion property of PVP polymer. On the other hand, the mucoadhesion values rose a little after the herbal oils were incorporated. Thus, these herbal oils can be incorporated in the nanofiber mats without any negative effects on the mucoadhesion property of PVP. 


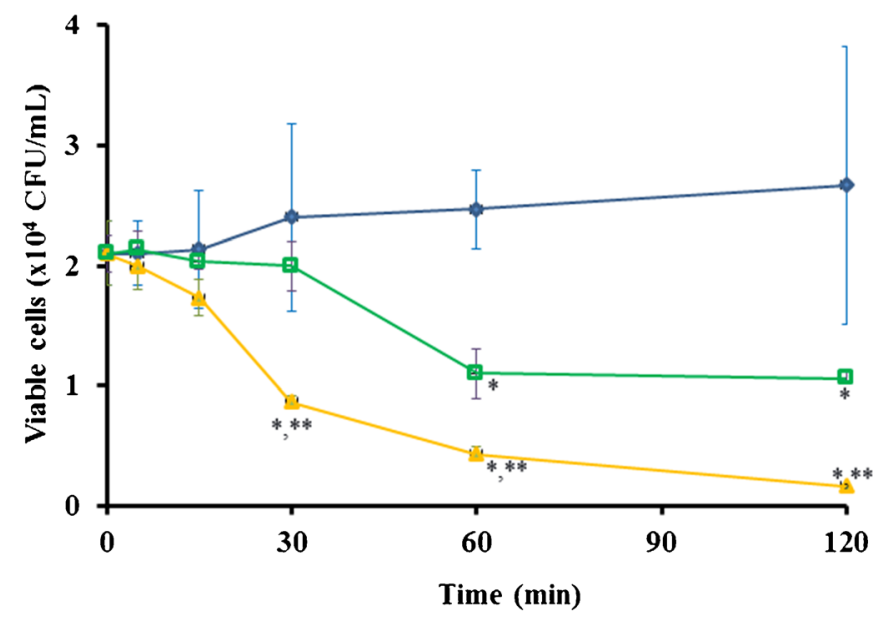

Fig. 7. Time-kill plots of C. albicans ATCC 90028 versus the treatment time: (diamond) control, (square) $30 \%$ betel oil loaded nanofiber mats and (square) $30 \%$ clove oil loaded nanofiber mats. The data are expressed as mean \pm standard deviation from three independent experiments. *Statistically significant $(P<0.05)$ from control. **Statistically significant $(P<0.05)$ from clove oil loaded nanofiber mats

\section{In vitro Release}

The release characteristics of the herbal oil loaded nanofiber mats are presented in Fig. 6. It is clearly observed from the release profiles that both betel oil and clove oil displayed very fast release from the nanofiber mats followed by gradual release. Almost $50 \%$ of the betel and clove oil that was incorporated in the nanofiber mats released to the release medium within $1 \mathrm{~min}$. This is due to the very fast dissolving property of PVP polymer (26). The betel oil loaded nanofiber mats and the clove oil loaded nanofiber mats exhibited quite similar release patterns except that the betel oil loaded nanofiber mats had faster release rate in the initial period. This might be due to the high loading amount of betel oil in the nanofiber mats.

\section{Antifungal Studies}

The susceptibility testing of betel oil and clove oil was performed using a broth dilution assay to determine MIC and MFC values against C. albicans ATCC 90028. Betel oil and clove oil were strongly active against $C$. albicans with MIC values of 0.781 and $0.049 \mu \mathrm{g} / \mathrm{ml}$ and the MFC values of 0.781 and $0.092 \mu \mathrm{g} / \mathrm{ml}$, respectively.

Time-kill analyses were performed to evaluate the antifungal activity of the herbal oil loaded nanofiber mats by determining the exposure time required to kill standardized microbial inoculums. The time-kill plots of nanofiber mats containing betel oil or clove oil and the control sample are displayed in Fig. 7. As compared to the control sample, the nanofiber mats loaded with betel oil or clove oil can inhibit the

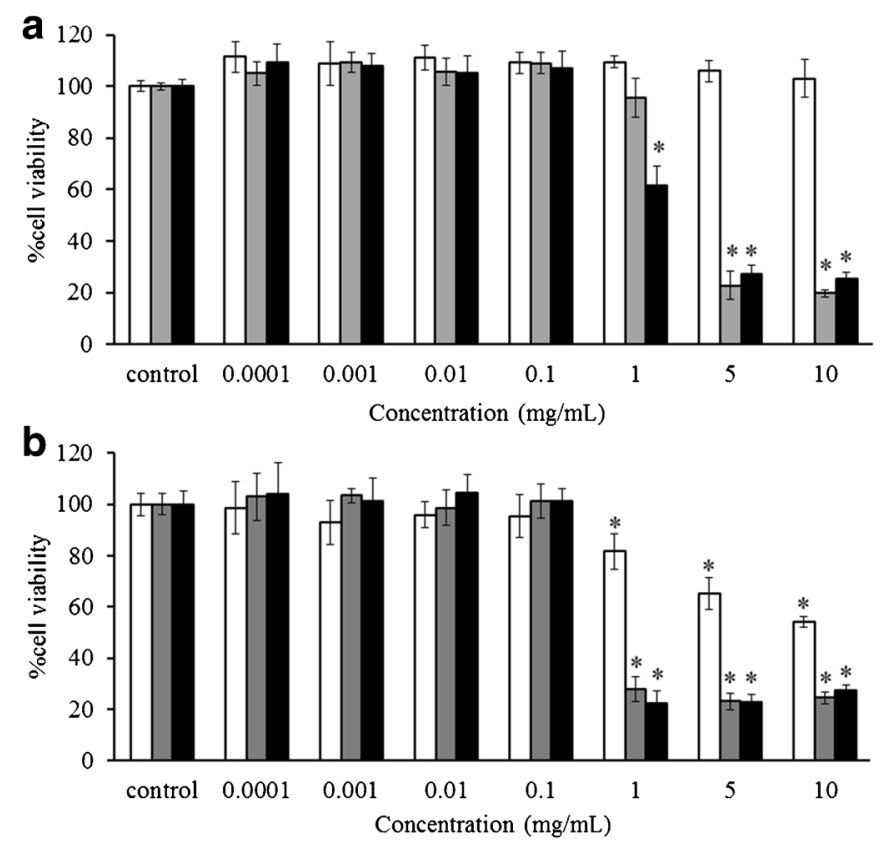

Fig. 8. In vitro cytotoxicity of $(\square)$ blank nanofiber mats, clove oil loaded nanofiber mats, and betel oil loaded nanofiber mats against HGF cells after incubation for $\mathbf{a} 2 \mathrm{~h}$ and $\mathbf{b} 24 \mathrm{~h}$. *Statistically significant $(P<0.05)$ from control 
growth of candida cell after contact with only few minutes. The betel oil loaded nanofibers started inhibiting the Candida cells since 5 min after contact. The very fast dissolving property of PVP polymer resulted in very fast release of the oils from the nanofiber mats and inhibited the Candida cells. Previous study reported that the rapid wetting/disintegration of the $\mathrm{PVP} / \mathrm{HP} \beta \mathrm{CD}$ nanofibers leading to free $\mathrm{CZ}$ rapidly released from the mats caused faster antifungal activity (26). In addition, the betel oil loaded nanofiber mats exhibited rapid antifungal activity and displayed significantly faster antifungal activity at 30 to $120 \mathrm{~min}$ after contact compared to the clove oil loaded nanofiber mats. These results might be due to the greater amount of the betel oil contained in the nanofiber mats with approximately 3 times higher than that of clove oil.

\section{Cytotoxicity Studies}

The in vitro cytotoxicity of the blank nanofiber mats and herbal oil loaded nanofiber mats were determined using MTT assay. This investigation was performed to evaluate the biocompatibility of the prepared systems and their potential application for oral candidiasis. The cytotoxicity of the prepared systems was assessed at various concentrations (0.0001 to $10 \mathrm{mg} / \mathrm{ml}$ ). The results from the test are illustrated in Fig. 8. Figure $8 \mathrm{a}$, b shows the cell viabilities of the extraction medium from blank nanofiber mats and herbal oil loaded nanofiber mats at the mats concentrations from 0.0001 to $10 \mathrm{mg} / \mathrm{ml}$ after incubation at $\mathrm{pH} 7.4$ for 2 and $24 \mathrm{~h}$, respectively, against the HGF cells. There was a significant decrease in the cell viability when the HGF cells were incubated with high concentration of the herbal oil loaded mats $(1-10 \mathrm{mg} / \mathrm{ml})$ compared to the control $(p<0.05)$. This finding might be because the amount of herbal oil was too high and toxic to fibroblast cells. However, the clove oil loaded nanofiber mats were safe for use at the concentration of 0.0001 to $1 \mathrm{mg} / \mathrm{ml}$ for $2 \mathrm{~h}$ and at 0.0001 to $0.1 \mathrm{mg} / \mathrm{ml}$ for $24 \mathrm{~h}$. On the other hand, the betel oil loaded nanofiber mats exhibit higher toxicity due to the higher oil loading. They were safe for use at the concentration of 0.001 to $0.1 \mathrm{mg} / \mathrm{ml}$ for 2 and $24 \mathrm{~h}$. In fact, the nanofiber mats are fast dissolving and would be contacted with the mouth for only few minutes. This could help reduce the toxicity of the herbal oils against the oral cells.

\section{CONCLUSION}

In this study, the nanofiber mats containing herbal oils with antifungal activity were successfully fabricated via electrospinning process. The HP $\beta C D$ was employed to entrap the oil and reduce hygroscopic property of PVP. The oil incorporated in nanofiber mats exhibited very fast release and rapidly reduce the candida cell in vitro. These nanofiber mats may have potential to be used as a material for oral hygiene maintenance in denture stomatitis for oral candidiasis prevention. Further in vivo investigation should be done to confirm the clinical efficacy of these materials.

\section{ACKNOWLEDGMENTS}

The authors would like to thank the Commission of Higher Education (Thailand), the Thailand Research Funds through the Royal Golden Jubilee Ph.D. Program (Grant
No.PHD/0092/2554), the Thailand Research Funds and Faculty of Pharmacy, the Silpakorn University, and the Silpakorn University Research and development institute for their financial support.

\section{REFERENCES}

1. Pereira-Cenci T, Del BelCury AA, Crielaard W, Ten Cate JM. Development of Candida-associated denture stomatitis: new insights. J Appl Oral Sci. 2008;16(2):86-94.

2. Gendreau L, Loewy ZG. Epidemiology and etiology of denture stomatitis. J Prosthodont. 2011;20(4):251-60.

3. Figueiral MH, Fonseca P, Lopes MM, Pinto E, Pereira-Leite T, Sampaio-Maia B. Effect of denture-related stomatitis fluconazole treatment on oral Candida albicans susceptibility profile and genotypic variability. Open Dent J. 2015;9:46-51.

4. Johnson CC, Yu A, Lee H, Fidel PL, Noverr MC. Development of a contemporary animal model of Candida albicans-associated denture stomatitis using a novel intraoral denture system. Infect Immun. 2012;80(5):1736-43.

5. Maghrani M, Zeggwagh NA, Haloui M, Eddouks M. Acute diuretic effect of aqueous extract of Retamaraetam in normal rats. J Ethnopharmacol. 2005;99(1):31-5.

6. Sabzghabaee AM, Shirdare Z, Ebadian B, Aslani A, Ghannadi A. Clinical evaluation of the essential oil of Pelargonium graveolens for the treatment of denture stomatitis. Dent Res J. 2011;8(Supp11):S105-8.

7. Toprani R, Patel D. Betel leaf: revisiting the benefits of an ancient Indian herb. South Asian J Cancer. 2013;2(3):140-1.

8. Fazal F, Mane PP, Rai MP, Thilakchand KR, Bhat HP, Kamble $\mathrm{PS}$, et al. The phytochemistry, traditional uses and pharmacology of Piper Betel. linn (Betel Leaf): A pan-asiatic medicinal plant. Chin J Integr Med. 2014.

9. Himratul-Aznita WH, Mohd-Al-Faisal N, Fathilah AR. Determination of the percentage inhibition of diameter growth (PIDG) of Piper betle crude aqueous extract against oral Candida species. J Med Plant Res. 2011;5(6):878-84.

10. Nuñez L, Aquino MD. Microbicide activity of clove essential oil (Eugenia caryophyllata). Braz J Microbiol. 2012;43(4):1255-60.

11. Pramod K, Ansari SH, Ali J. Eugenol: a natural compound with versatile pharmacological actions. Nat Prod Commun. 2010;5(12):1999-2006.

12. Dagli N, Dagli R, Mahmoud RS, Baroudi K. Essential oils, their therapeutic properties, and implication in dentistry: a review. J Int Soc Prev Community Dent. 2015;5(5):335-40.

13. Mith H, Duré R, Delcenserie V, Zhiri A, Daube G, Clinquart A. Antimicrobial activities of commercial essential oils and their components against food-borne pathogens and food spoilage bacteria. Food Sci Nutr. 2014;2(4):403-16.

14. Ahmad N, Alam MK, Shehbaz A, Khan A, Mannan A, Hakim SR, et al. Antimicrobial activity of clove oil and its potential in the treatment of vaginal candidiasis. J Drug Target. 2005;13(10):555-61.

15. Parkash V, Maan S, Deepika, Yadav SK, Hemlata, Jogpal V. Fast disintegrating tablets: opportunity in drug delivery system. J Adv Pharm Tech Res. 2011;2(4):223-35.

16. Li X, Kanjwa MA, Lin L, Chronakis IS. Electrospun polyvinylalcohol nanofibers as oral fast-dissolving delivery system of caffeine and riboflavin. Colloids Surf B. 2013;103:182-8.

17. Tiwari G, Tiwari R, Rai AK. Cyclodextrins in delivery systems. J Pharm Bioallied Sci. 2010;2(2):72-9.

18. Tonglairoum P, Chuchote T, Ngawhirunpat T, Rojanarata T, Opanasopit P. Encapsulation of plai oil/2-hydroxypropyl-betacyclodextrin inclusion complexes in polyvinylpyrrolidone (PVP) electrospunnanofibers for topical application. Pharm Dev Technol. 2014;19(4):430-7.

19. Valle D, Martin EM. Cyclodextrins and their uses: a review. Process Biochem. 2004;39:1033-46.

20. Tonglairoum P, Ngawhirunpat T, Rojanarata T, Opanasopit P. Lysozyme-immobilized electrospun PAMA/PVA and PSSAMA/PVA ion-exchange nanofiber for wound healing. Pharmaceutical development and technology. 2014:1-8. 
21. Homaeigohar S, Buhr K, Ebert K. Polyethersulfoneelectro spunnanofibrous composite membrane for liquid filtration. J Membr Sci. 2010;365:68-77.

22. Tonglairoum P, Ngawhirunpat T, Rojanarata T, Kaomongkolgit R, Opanasopit P. Fabrication of a novel scaffold of clotrimazolemicroemulsion-containing nanofibers using an electrospinning process for oral candidiasis applications. Colloids Surf B. 2015;126:18-25.

23. Bhardwaj N, Kundu SC. Electrospinning: a fascinating fiber fabrication technique. Biotechnol Adv. 2010;28(3):325-47.

24. Samprasit W, Rojanarata T, Akkaramongkolporn P, Ngawhirunpat T, Kaomongkolgit R, Opanasopit P. Fabrication and in vitro/in vivo performance of mucoadhesive electrospun nanofiber mats containing $\alpha$-mangostin. AAPS PharmSciTech. 2015;16(5):1140-52.

25. Singh S, Jain S, Muthu MS, Tiwari S, Tilak R. Preparation and evaluation of buccalbioadhesive films containing clotrimazole. AAPS PharmSciTech. 2008;9(2):660-7.

26. Tonglairoum P, Ngawhirunpat T, Rojanarata T, Kaomongkolgit R, Opanasopit P. Fast-acting clotrimazole composited PVP/ HPbetaCD nanofibers for oral candidiasis application. Pharm Res. 2014;31(8):1893-906.
27. Ferreres F, Oliveira AP, Gil-Izquierdo A, Valentão P, Andrade PB. Piper betle leaves: profiling phenolic compounds by HPLC/ DAD-ESI/MS(n) and anti-cholinesterase activity. Phytochem Anal. 2014;25(5):453-60.

28. Rana IS, Rana AS, Rajak RC. Evaluation of antifungal activity in essential oil of the Syzygium aromaticum (L.) by extraction, purification and analysis of its main component eugenol. Braz J Microbiol. 2011;42(4):1269-77.

29. Basha MA-F. Magnetic and optical studies on polyvinylpyrrolidone thin films doped with rare earth metal salts. Polym J. 2010;42(9):728-34.

30. Al-Zein H, Sakeer K, Alanazi FK. Designing an extended release waxy matrix tablet containing nicardipine-hydroxy propyl $\beta$ cyclodextrin complex. Saudi Pharm J. 2011;19(4):245-53.

31. Kadam SS, Waghmare JS. Identification of major volatile (essential oil) constituents of Carrom seeds and clove buds. IJSRR. 2014;3(2):85-94.

32. Rahimi AA, Ashnagar A, Nikoei H. Isolation and characterization of 4-allyl-2methoxyphenol (eugenol) from clove buds marketed in Tehran city of Iran. Int $\mathbf{J}$ Chem Tech Res. 2012;4(1):105-8. 